\title{
À Procura das Geografias de Género e Sexualidadle em Portugal
}

\author{
Looking for Geographies of Gender and Sexuality in Portugal
}

\author{
Nuno Rodrigues \\ ISCTE/Instituto Universitário de Lisboa - Portugal \\ nmdrodrigues@gmail.com
}

\section{Resumo}

O presente artigo visa apresentar uma perspectiva histórica das geografias de género e sexualidade em Portugal. Será privilegiada uma abordagem relacional, partindo da consideração de algumas críticas e inovações desenvolvidas na área em questão, ao mesmo tempo que tendo em consideração a sua diversidade interna, de forma a analisar a recepção das mesmas por parte das geografias de género e sexualidade em Portugal. Num primeiro momento, procura-se traçar uma pequena síntese de tais questões, tanto no que diz respeito às temáticas mais 'estritamente' associadas ao género e sexualidade, bem como a consideração das perspectivas epistemológicas que se associam a esta área, em particular através do recurso às críticas trazidas por correntes como o pósestruturalismo, feminismo(s) e teoria queer. Posteriormente, o objectivo passa por considerar os trabalhos das geografias de género e sexualidade portuguesas, procurando não só fazer uma breve descrição dos seus principais temas, como uma breve análise dos mesmos a partir das abordagens teóricometodológicas apresentadas anteriormente.

Palavras-chave: Género; Sexualidade; Teoria Queer.

\begin{abstract}
This article presents a historical perspective on the geographies of gender and sexuality in Portugal. A relational approach is privileged, parting from the consideration of some criticism and innovations developed in the area in question, while taking into account its internal diversity, in order to analyze its reception by the geographies of gender and sexuality in Portugal. Initially, the aim is to draw a short summary of these issues, both in relation to the themes more 'strictly' associated with gender and sexuality, as well as under epistemological perspectives associated with this area, particularly through the critical currents brought by post-structuralism, feminism(s) and queer theory. Subsequently, the aim is to consider the work of the Portuguese geographies of gender and sexuality, looking not only for a brief description of its main themes, but also for a brief analysis of the data under the theoretical and methodological approaches presented above.
\end{abstract}

Keywords: Gender; Sexuality; Queer theory. 


\section{Introdução}

Este trabalho começa com uma referência intertextual, seja no '(re)uso' do título de um artigo do geógrafo João Sarmento (2008), bem como citação que se segue e que contextualiza da seguinte forma esta área em Portugal:

A Geografia do género tem-se mantido bastante marginal, e a disciplina parece quase que ignorar a tenacidade dos recentes debates e desenvolvimentos internacionais. Exceptuando uma tese de doutoramento inovadora defendida há cerca de 15 anos por André, precedida de um desafio para animar a Geografia do género na qual trabalhos de Massey, McDowell e outros geógrafos e geografas anglo-americanos foram introduzidos (ver André 1990), muito pouco tem sido publicado. Contrariamente ao que sucede em Espanha (ver García-Ramon, Albet e Zusman 2003), os estudos do género nunca sulcaram um corte significativo na corrente dominante da geografia portuguesa, e as geografias feministas, da homossexualidade, da juventude e da infância, da deficiência, as geografias do quotidiano ou da masculinidade, estão notoriamente ausentes." (SARMENTO, 2008, p. 591).

Tal como referido, os trabalhos de Isabel André podem ser tomadas como o início das Geografias de Género e Sexualidade em Portugal ${ }^{1}$. Para lá da importância dessa delimitação temporal e da referência ao trabalho em causa, é de salientar, contudo, o tempo, de aproximadamente 15 anos, que vai desde os trabalhos iniciais de Isabel André (ANDRÉ e FONSECA, 1989; ANDRÉ, 1990) até às publicações posteriores (MOREIRA, 2003) de outras geógrafas e geógrafos a trabalhar sobre género e sexualidade em Portugal. Sendo que este sinal poderá ser visto como revelador, em termos globais, do

contexto social e académico da altura e da abertura e recepção dessas temáticas na Geografia Portuguesa ${ }^{2}$, mantendo-se tal área como relativamente 'marginal' apesar da recente e diversa dinâmica verificada. Neste sentido, o objectivo principal e pessoal deste artigo passa por procurar conhecer mais sobre essa área, em particular ao nível de quem são os autores, e quais os temas e os debates tidos nas geografias de género e sexualidade portuguesas.

\section{Discussão Metodológica e Posicionalidade}

De forma a responder ao objectivo anteriormente exposto, o de traçar uma breve síntese das Geografias de Género e Sexualidade portuguesas, a principal dificuldade metodológica, a um nível mais 'prático', prendeu-se com a pesquisa e acesso ${ }^{3}$ dos diferentes trabalhos ${ }^{4}$. Ao nível da selecção posteriormente feita, esta teve em consideração não só trabalhos onde as dimensões de género e sexualidade estavam presentes, mas, também, a forma como tais dimensões eram problematizados. Sendo que os critérios para tal selecção se encontraram 'condicionados' tanto pela pouca produção bibliográfica existente nessa área na geografia portuguesa, pela forma como os conceitos de 'género' e 'sexualidade' (não) são trabalhados pela Geografia Portuguesa na sua generalidade, como pela procura de uma análise relacional e comparativa. Desta forma, a escolha recaiu por ter, como critério ${ }^{5}$ principal, a selecção de trabalhos onde as dimensões de género e sexualidade ocupassem um espaço central na análise, ao nível dos temas/objectos, sendo conferindo um menor peso à forma como tais conceitos eram percepcionados e posteriormente trabalhados. Associado a estas questões, é de referir o risco, existente e reconhecido, de algum trabalho ter 'escapado' e de ter sido 
cometido alguma injustiça e/ou invisibilidade ${ }^{6}$ a este nível, ou de ter sido considerado algum trabalho que não o deveria ter sido. Um outro desafio prendeu-se com a necessidade de sintetizar, num artigo, os diferentes trabalhos, sendo que tal síntese não se encontra isenta de erros, e, como tal, existe uma dimensão ética que foi tida em consideração, ao nível da 'representação' das ideias em causa, mas que não é por si garantia de qualquer 'fiabilidade' em tal representação.

Antes de procurar responder a tais objectivos/perguntas, importa ainda discutir alguns pontos. Em primeiro lugar, importa questionar como alguém que se autoidentifica como masculino ao nível de género e heterossexual, num contexto que é patriarcal e heteronormativo ${ }^{7}$, poderá ter não só 0 interesse, como ser capaz de trabalhar sobre tais questões de um ponto de vista que pretende ser não-normativo. Uma possível resposta, entre várias possíveis, poderá estar no reconhecimento não só de identidades fluídas e não estanques, mesmo que tal referência possa ter como reverso a negação da importância de tais identidades no actual contexto de relações de poder, nem que seja pela forma como tais identidades possam ser percepcionadas por outros, inclusivamente, de forma diferenciada daquela que é a autoidentificação de uma dada pessoa. Uma resposta, talvez mais 'satisfatória' para a posição do investigador em causa, poderá encontrar-se na referência a uma possível identidade heteroqueer, "(...) heterossexuais que rejeitam activamente os privilégios associados à heteronormatividade (...)" (SANTOS, 2005, p. 1), ainda que seja de questionar não só o grau de questionamento dos privilégios conferidos pelas normas socais em causa, como, igualmente, o grau de envolvimento no activismo feminista e LGBT.

Por último, é igualmente de questionar como alguém que 'fala' de 'fora' da comunidade académica/científica, mesmo que estudante, poderá ter a pretensão de trabalhar e fazer uma análise crítica sobre esta área. Para tal objectivo, surgiu, igualmente, a necessidade de questionar o que 'são' as 'geografias de género e sexualidade', questionamento este que ocorreu, simultaneamente, ao reconhecimento, por parte do autor dessas linhas, do facto de se tratar de uma área que este se encontra, longe de 'dominar' em profundidade. Reconhecendo tais limitações e igualmente como consequência das mesmas, é de salientar que este processo de investigação foi, simultaneamente, um processo aprendizagem, e que não parte, como tal, de uma teoria 'certa' e de uma análise 'objectiva' em termos absolutos. Ou seja, torna-se necessário assumir a construção do objecto de estudo que se pretendia 'analisar', numa relação sujeito-objecto não neutra e mediada por várias razões, sendo de reconhecer que o referido 'objecto' construiu, igualmente, o 'sujeito' da investigação. Assim sendo, e retomando os pontos anteriormente referidos é de admitir uma análise necessariamente parcial, subjectiva e incorporada, influenciada por aspectos sociais e culturais.

\section{Género(s) e sexualidade(s)}

A abordagem considerada no presente trabalho, relativamente as 'categoria' de 'género' e 'sexualidade', baseou-se na forma como tais 'conceitos' têm vindo a ser trabalhados pelos denominados 'feminismo(s) de terceira vaga' e pela teoria queer ${ }^{8}$ (SANTOS, 2006; SHARP, 2004; OLIVEIRA et al, 2009). Correndo o risco de simplificar as discussões em causa, bastante diversas e em contínuo processo, essas visões podem caracterizar-se por uma crítica a uma oposição binária entre 'homem' e 'mulher', 'género' e 'sexualidade', 'masculino' e 'feminino', 'heterossexual' e 'homossexual', 
contestando assim uma visão dicotómica que não é só característica de uma 'epistemologia masculina', mas também formada e reproduzida dentro de relações de poder patriarcais e heteronormativos. Uma visão binária que parte da dicotomia entre 'sexo' como biológico e o 'género' como social e culturalmente, sendo que, como refere Isabel Pato e Silva: "[a] distinção feminista entre corpos naturais (sexo) e corpos sociais (género) falhou porque os corpos sociais se mantiveram como categorias a priori (BUTLER, 1990) baseadas em falsos fundamentos" (SILVA, 2010, p. 107). Ora, o que é salientado pelos contributos referidos, é que o conceito de género não pode ser visto de forma isolada, mas complexa e relacional com outras dimensões, sendo necessário atender à fluidez e instabilidade entre corpo, género, sexualidade e desejo. Desta forma, é feita uma crítica às visões essencialistas e imóveis sobre tais identidades, visões estas que são (re)produtoras de normatividades, sendo privilegiado, ao invés, uma abordagem relacional que tenha em consideração a fluidez e a 'instabilidade' de tais 'categorias' e 'fronteiras'.

\section{Epistemologia(s) e Geografia(s)}

Num artigo relativamente recente, Eduardo Brito Henriques (2007), recuperando e aprofundando parte de algumas ideias expostas anteriormente (HENRIQUES, 1996), traça um breve quadro das diferentes perspectivas epistemológicas que marcam a geografia humana nas décadas mais recentes, salientado que "[s]e algum facto há que pode caracterizar a Geografia Humana contemporânea é a enorme diversidade de perspectiva teóricas e de enfoques possíveis que admite." (HENRIQUES, 2007, p.113). O autor refere que o principal debate não está no objecto, o qual, segundo o autor, diz respeito à “(...) estudar a Terra enquanto lugar que as populações humanas souberam tornar habitável e habitado" (HENRIQUES, 2007, p. 114), mas encontra-se, isso sim, nas diferentes perspectiva teórico-metodológicas para o estudo de tal relação, sendo que: "[n]estas várias alternativas em que se desdobra a Geografia de hoje estão em jogo sensibilidades filosóficas e pontos de vista em tensão, nem todos conciliáveis, e alguns até contraditórios.” (HENRIQUES, 2007, p. 114). Aprofundando esta discussão epistémica da Geografia contemporânea, o autor salienta as perspectivas que, podendo ser caracterizadas como influenciadas pelo pós-estruturalismo e pela influência e herança do pensamento filosófico de Nietzsche, suscitam questões ao nível da 'representação' da 'realidade' por parte da 'ciência', referindo que tais perspectivas chegam ao "(...) extremismo de recusar a simples possibilidade de acesso ao conhecimento de uma realidade 'pura', isto é, extrateórica ou metanarrativa." (HENRIQUES, 2007, p. 115). Sendo que, e pelo menos no caso do pós-estruturalismo, a crítica não se esgote nos pontos já referidos, estendendo-se, entre outros, às formas de pensamento dicotómico e à criação e reprodução de categorias/significados essencialistas, imóveis e fixistas.

Como refere Donna Haraway, na sua crítica ao conhecimento que se apresenta como 'objectivo' e 'neutral', conhecimento este que parte de uma relação dicotómica entre sujeito e objecto, associado a uma 'epistemologia masculina' que tende a (re)produzir desigualdades sociais, a autora refere que o conhecimento é e deve ser tomado como sempre situado, dado que 'conhecer o mundo real' não depende assim de uma lógica de 'descoberta' mas de uma relação social de 'diálogo' carregada-depoder. $\mathrm{O}$ mundo não fala, nem desaparece a favor de um meta descodificador. Os códigos do mundo não estão estáticos, esperando ser 
lidos, nenhuma doutrina particular, representação, descodificação ou descoberta garante o que quer que seja " (HARAWAY, 1991, p. 198 - 199, cit. THRIFT, 1996, p.x)" (SILVA, 2010, p 110 - 111).

Tais críticas, tanto a de uma crítica da representação ${ }^{9}$, como a crítica à denominada 'epistemologia masculina'10, bem como a crítica da necessidade de considerar $\mathrm{o}$ conhecimento como sempre situado e dependente da posicionalidade de um autor(a) ${ }^{11}$, sendo que todos estas críticas e contributos apresentem várias ligações/intersecções entre si, têm vindo a ser debatidas na geografia contemporânea, e, em particular, nas geografias de género e sexualidade.

Por sua vez, é igualmente de referir o desafio lançado à geografia por Larry Knopp (2007, p. 27 - 28), no seu artigo: "Queering the geographical imagination", dividido em 5 grandes pontos. Um primeiro, que consiste no ultrapassar a oposição entre abordagens materialísticas e discursivas, salientando que o discursivo é sempre material e o material sempre discursivo. No seguimento da ideia anterior, o abandono de tal dicotomia implica a necessidade de considerar, como recursos igualmente válidos e integrados no processo de conhecimento, o 'corpo, sentimento, emoção e desejo'. O terceiro ponto, diz respeito à necessidade de expandir o campo empírico, de forma a incluir realidades tradicionalmente não abordadas na geografia, como seja a 'fluidez, incompletude, moralidades, desejo e incorporação'. Em quarto lugar, existe a necessidade de uma pesquisa mais humildade no que aos seus objectivos diz respeito, e, em particular, o reconhecimento de que as práticas e conhecimentos produzidos se encontram sempre num processo de (trans)formação, e nunca completos. Por último, o autor advoga a necessidade de alterar as imaginações geográficas-ontológicas, isto para que os objectos de estudo passem a ser abordados de forma mais relacional e topológica do que de forma autónoma e discreta, mais reflexiva do que objectiva e mais humildade do que ambiciosa.

Estas reflexões, como não poderia deixar de ser, reflectiram-se na importância da prática de estratégias metodológicas (GREGORY et al, 2009; MCDOWELL, 1992) atentas às relações que se estabelecem entre sujeito e objecto, da atenção conferida às várias (in)visibilidades que possam estar em causa, à promoção de uma abordagem relacional, considerando as relações de poder envolvidas e o contexto em que a investigação decorre, e os processos (re)produtores de diferença e, se possível, procurando desafiar esses mesmos, dando 'voz' aos grupos sociais 'estudados' e procurando promover processos de enpowerment. É ainda, de salientar a discussão, em particular advinda dos contributos da teoria queer, para que as estratégias metodológicas ${ }^{12}$ consideradas tenham em consideração as ontologias que partam de formas de pensamento binário, advogando a necessidade de ter em atenção uma abordagem mais complexa, utilizando metodologias que questionem e (des)construam as posições que se apresentam como 'objectivas' e portadoras de 'Verdade' (MANNING, 2009). Além disso, tende a ser igualmente reforçada a ideia de uma maior reflexividade por dos autores(as), bem como o surgimento de estratégias metodológicas assentes numa abordagem interseccional ${ }^{13}$. Face ao ferido, não é de estranhar que a preferência vá para a utilização de metodologias qualitativas, como seja a utilização de entrevistas e pesquisa de terreno/etnografia (MCDOWELL, 1992), ainda que esta preferência não deva ser visto de uma forma dicotómica com as quantitativas, até pelas possibilidades de complementaridade entre as duas que tendem 
a ser salientadas. A melhor distinção talvez não seja as que se estabelecem entre qualitativo-quantitativo, mas sim a diferença existente entre métodos intensivos ${ }^{14} \mathrm{e}$ extensivos, sendo de referir que nem todos os métodos intensivos são qualitativos e que nem todos os métodos extensivos são quantitativos.

\section{Análise}

\section{Temas}

As Geografias de Género e Sexualidade em Portugal caracterizam-se por uma diversidade temática, sendo de destacar os trabalhos que se associam essa área através de um estudo relacional com outras dimensões, como sejam Ambiente (LOPES, 2010; LOPES e CUNHA, 2012; QUEIRÓS, 2010b; QUEIRÓS e GASPAR, 2009a, 2009b), Casamento (CRAVIDÃO e SANTOS, 2010a, 2010b; ANDRÉ e FONSECA, 1989), Conflitos/Relações Internacionais (MEDEIROS, 2010), Corpo (AZEVEDO et al, 2009; ALVES, 2013; NADAIS e SANTOS, 2012), Emprego/Trabalho (ANDRÉ, 1993; NOSSA, 2001; PEREIRA, 2008, 2011, 2013; PEREIRA e VASCONCELOS, 2008; PEIXOTO et al, 2005), Espaço Público (FERREIRA, 2010, 2011a, 2011b, 2012; FERREIRA e SALVADOR, 2010; VIEIRA, 2009, 2010a, 2011a, 2011b, 2011c, 2011f; MOREIRA, 2003, 2010), Espacialidades Urbanas (VIEIRA， 2010a， 2010b，2011b，2011c, 2011d, 2011f; MOREIRA, 2003， 2010; MOREIRA e SANTOS, 2008; MENDES, 2010), (In)Visibilidade(s) (FERREIRA, 2010, 2011a, 2011b, 2012; FERREIRA e SALVADOR, 2010, 2012; VIEIRA, 2009, 2010a, 2011a, 2011c, 2011d, 2011f), Lazer (MOREIRA e SANTOS, 2008; NADAIS e SANTOS, 2012; ANDRÉ e HENRIQUES, 1992), Moda (ALVES, 2013), Migrações (VIEIRA, 2011a; MALHEIROS et al, 2010,
2011; PEREIRA, 2008，2011，2013; PEREIRA e VASCONCELOS, 2008; PEIXOTO et al, 2005; CRAVIDÃO e SANTOS, 2010a, 2010b), Planeamento (QUEIRÓS, 2010a, 2011，2012), Saúde (NOSSA, 1995), Transportes (QUEIRÓS e COSTA, 2012; QUEIRÓS e GASPAR, 2009a, 2009b), Turismo (SARMENTO e ETEMADDAR, 2009; VIEIRA, 2009).

\section{Género e Sexualidade}

No que diz respeito à consideração de como os conceitos de género e sexualidade são percecionados e posteriormente trabalhos, é de referir que o uso do conceito/categoria de género tende a ser feito segundo um ponto de vista binário ${ }^{15}$ (André, 1990; André, 1993; André e Fonseca, 1989; André e HENRIQUES, 1992; MOREIRA, 2003, 2010; CRAVIDÃO e SANTOS, 2010a, 2010b; MEDEIROS, 2010; MENDES, 2010; MALHEIROS et al, 2010, 2011; LOPES, 2010; LOPES e CUNHA, 2012; PEREIRA, 2008, 2011, 2013; PEREIRA e VASCONCELOS, 2008; PEIXOTO et al, 2005). Apesar de, na maior parte das análises, esta visão ter em conta as diferenças de género existentes num contexto de relações de poder desiguais, a mesma poderá ser, contudo, criticada por partir de uma lógica binária de género que irá influenciar o restante trabalho. Ocorre, ainda, a tendência para que, muitas vezes, 'mulher' surja como 'conceito/categoria' apriorística, por vezes representada/'referenciada' a partir de 'dados estatísticos'. Além disso, e ainda que não procurando opor uma área à outra, até pela fluidez já referida, ocorre um maior destaque ao nível da análise das relações de género, destacando a dimensão social deste processo e a forma como se materializa espacialmente ${ }^{16}$, e uma menor consideração das dimensões associadas à sexualidade. Em Portugal, a sexualidade surge como a categoria analítica central apenas nos 
trabalhos de Catarina Nadais e Norberto Santos $\quad(2012)^{17}$, Eduarda Ferreira (FERREIRA，2010a，2011a，2011b，2012; FERREIRA e SALVADOR, 2010, 2012), e Paulo Jorge Viera (2009, 2010a, 2010b, 2011a, 2011b, 2011c, 2011d, 2011f) - sendo de destacar os contributos dados por estes últimos dois autores, responsáveis pela introdução em Portugal das relações entre (in)visibilidade, espaço e orientações sexuais LGBT, destacando as relações de poder envolvidas, e a importância de tais espaços na (re)produção e expressão de orientações sexuais.

\section{Metodologia(s)}

No que diz respeito às estratégias metodológicas, existe, de forma geral, uma preferência para a utilização de metodologias qualitativas; sendo que, quando a análise incorpora métodos quantitativos, esta ocorre em complementaridade às metodologias qualitativas igualmente utilizadas, o que se traduz numa situação de métodos mistos/triangulação (ANDRÉ, 1993; ANDRÉ e HENRIQUES, 1992; MOREIRA, 2003, 2010; CRAVIDÃO e SANTOS, 2010a, 2010b; QUEIRÓS e GASPAR, 2009a, 2009b; QUEIRÓS e COSTA, 2012). No entanto, na maioria das opções, a tendência passa por uma problematização da relação entre sujeito e objecto, da promoção de uma abordagem relacional, da consideração das relações de poder e de 'diferença' envolvidas, bem como das possíveis situações de invisibilidade que certas abordagens metodológicas poderão originar, questão estas que se relacionam com a referida crítica à 'epistemologia masculina'. Sendo de destacar, em particular, a atenção dada a este ponto por Eduarda Ferreira (FERREIRA, 2010, 2011a, 2012; FERREIRA e SALVADOR, 2012), sendo que as metodologias qualitativas exploradas nestes casos apresentam a possibilidade de uma pesquisa co-produzida, não normativa, sujeita a diferentes representações (percepções e interpretações), visibilidades e subjectividades, como apresenta ainda a potencialidade, que se poderá considerar performativa, de criação de outros espaços, não-heteronormativos.

\section{Epistemologia(s)}

Nos diversos trabalhos, e em particular nos primeiros na área das geografias de género (ANDRÉ, 1990, 1993; MOREIRA, 2003), é feita uma crítica à denominada 'epistemologia masculina', tendo como base a ausência/invisibilidade de determinados temas e grupos sociais no conhecimento e investigação geográfica, a qual se encontra relacionada com posições epistemológicas que se apresentam como 'neutras' e 'objectivas'. Esta crítica, que se reflectiu em alguns dos trabalhos produzidos, defendia o reconhecimento da posicionalidade do investigador(a) de forma a evitar falsas noções de neutralidade - particularmente salientada por Eduarda Ferreira (FERREIRA, 2010, 2011a, 2011b, 2012; FERREIRA e SALVADOR, 2010, 2012) -, a crítica da utilização de categorias dicotómicas e essencialistas, a defesa da adopção de um ponto de vista relacional na análise de diferentes temas, em particular daqueles que tenderam a ficar de fora dos paradigmas da Geografia, da consideração da relação que se estabelece entre sujeito-objecto, e de uma estratégia metodológica capaz de ultrapassar 'invisibilidades'.

A crítica de análises dicotómicas é destacada, desde logo, nos trabalhos de Isabel André, defendendo a autora uma análise integrada, tendo em consideração múltiplas dimensões, a qual considera ser possível através de uma perspectiva que parta do território ${ }^{18}$. A problematização apresentada em alguns dos trabalhos coordenados por 
Margarida Queirós relativamente à relação entre sociedade e território ${ }^{19}$, debatendo-se uma forma de planeamento capaz de ultrapassar análises sectoriais e dicotómicas e de adoptar uma perspectiva transversal, uma 'transversalidade de género' - a qual poderá ter proximidades ao nível de uma análise intersecional -, considerando, assim, as aspirações e necessidades dos diferentes grupos de forma integrada/intersecional/transversal, nãodiscriminatória e inclusiva, de forma a "(...) poder fazer uma distribuição adequada de bens e recursos e conceber instrumentos que levem à prática essas políticas." (QUEIRÓS, 2012, p. 143), dado que "[o]s recursos do território devem ser equitativamente acessíveis, só assim o princípio da igualdade social se aplica." (SILVA e VIEIRA, 2012, p. 187). $\mathrm{Ou}$ os contributos apresentados em Azevedo et al (2009), relativas a uma abordagem do espaço que parta do corpo, da sua consideração de forma reflexiva nas diferentes fases do processo de conhecimento $^{20}$, é não só necessária dado que a sua presença influencia inevitavelmente tal processo, mas como essta abordagem permite ainda uma análise não dicotómica/binária, integrada e relacional. De destacar, ainda, a procura de uma geografia não dicotómica e não normativa nos trabalhos de Paulo Jorge Vieira, associando tais questões à necessidade de se assumir posicionalidade do investigador(a), de ser tido em consideração às relações de poder e (in)visibilidade, na incorporação da reflexividade e intersecionalidade na análise, bem como na necessidade de se evitar conceitos essencialistas/fixistas/imóveis de espaço, lugar, identidade, ente outros.

Alguns dos trabalhos analisados revelam a procura de outros temas e análise de grupos sociais até então 'invisíveis', e/ou a capacidade de realizar uma outra abordagem relativamente a temas e objectos mais 'tradicionais' na geografia. Desde logo, é de destacar o caso de Isabel André (1993), ao demonstrar a pertinência e a dimensão social do trabalho doméstico. O caso das relações laborais analisadas por Sónia Pereira (PEREIRA, 2008, 2011, 2013; PEREIRA e VASCONCELOS, 2008; PEIXOTO et al, 2005) ao nível de trabalhadoras imigrantes, em particular nos processos de precariedade e exploração a vários níveis a que estão sujeitas. A problematização feita por Ana Alves (2013) sobre a Moda e as suas representações e papel da Moda na sociedade contemporânea. A presença da dimensão de género na análise de relações internacionais/conflitos (MEDEIROS, 2010). A introdução da dimensão de género em problemáticas tradicionalmente mais associadas à Geografia Física/Ambiente (LOPES, 2010; LOPES e CUNHA, 2012; QUEIRÓS, 2010b). Bem como a capacidade de 'subverter' áreas tradicionalmente tidas como 'masculinas' e 'heteronormativas', como é o caso dos trabalhos coordenados por Margarida Queirós na área do planeamento.

No entanto, é de referir que alguns dos trabalhos na área das geografias de género e sexualidade em Portugal continuam a revelar um objecto de estudo, e uma abordagem ao mesmo, reveladora de certos traços associados a uma 'epistemologia masculina', seja por revelar algumas invisibilidades na análise $^{21}$, pela utilização dicotómica de alguns conceitos - em particular, o de género, as estratégias metodológicas escolhidas em particular quando os trabalhos basearam grande parte da sua argumentação/discussão em métodos quantitativos -, ou pela possível visão normativa ${ }^{22}$.

\section{Notas Finais}

De forma muito sucinta, é possível referir que as geografias de género e sexualidade em Portugal têm reconhecido uma dinâmica 
diversa, conquistando cada vez mais autores e autoras, com temas e abordagens diversas. Essa dinâmica encontra-se inserida num processo recente, mas que parece ter a tendência para conquistar cada vez mais centralidade na Geografia Portuguesa.

Não explorando muito mais o tema, importa apenas referir que se poderá revelar útil e interessante, para a Geografia Portuguesa no seu todo, mas em particular ao nível da Geografia Social e Cultural, observar mais atentamente as ligações que já se estabelecem $^{23}$, e que, futuramente, se poderão estabelecer ainda com mais intensidade, entre as geografias de género e sexualidade e a restante Geografia Portuguesa. Sendo assim, seria interessante discutir as possíveis críticas e contributos que estas geografias trazem e poderão trazer, e incorporá-las, quando não a há um nível temáticos, pelo menos a há um nível mais epistemológico, seja na crítica de formas de pensamento dicotómico e normativo, na promoção de uma abordagem relacional, seja na crítica da utilização de conceitos essencialistas e dicotómicos, na atenção às relações de poder e a (in)visibilidades várias na consideração da posicionalidade do autor(a), entre outros pontos/problemáticas.

1 Contudo, provavelmente não se deverá supor, até pela dificuldade em ter presente toda a produção bibliográfica em causa, que anteriormente não tivessem sido realizados trabalhos com preocupações ao nível de género e sexualidade, mas sim que essas dimensões não tiveram uma problematização e centralidade capazes de justificar a sua consideração como Geografias de Género e/ou Sexualidade.

2 Apesar de não ser explorada neste artigo, é importante reflectir sobre a razão de uma análise 'nacional', análise que terá como 'objecto' 'algo' que daria pelo nome de Geografia Portuguesa. Em particular, é de questionar se tal Geografia Portuguesa seria definida pela nacionalidade de quem a faria, utilizando categorias a priori, e que neste caso seriam os geógrafos e geógrafas portuguesas, de preferência a trabalhar em 'território nacional'; ou se essa Geografia Portuguesa apresentaria uma qualquer característica 'diferenciadora' capaz de a identificar quando comparada com 'outras' geografias, integrando autores(as) de diferentes nacionalidades? Isto é, seria importante questionar o facto de este artigo priveligiar uma análise 'nacional', mesmo que com referência teórica a autore(as) 'estrangeiro(as)', e o que se 'perde' e 'ganha' na exploração do tema com a opção tomada de considerar como geografia portuguesa aquela que seria feita por autores(as) de nacionalidade portuguesa. Sendo que tal opção acabou por ter como consequência a não consideração de contributos de autores 'estrangeiros' em publicações 'nacionais', como é o caso de Richard Phillips (2007), Bradley Pink (2009), Petri Hottola (2004), Roberta Gilchrist (2009) ou Benedict Hoff (2009), mesmo que seja de considerar que tais autores apresentam perspectivas epistemológicas que, quando comparadas com a generalidade das geografias de género e sexualidade portuguesas, os diferenciavam claramente.

3 Faltam, entre outros, a análise a Roca e Leitão (2011) e Moreira (2008).

4 A pesquisa foi feita em vários repositórios online das diferentes instituições universitárias com departamentos de Geografia, em CVs dos diferentes investigadores(as) presentes nos centros de investigação de Geografia em Portugal, em actas de congressos portugueses e ibéricos de Geografia, em revistas portuguesas de geografia. Nesta fase, uma primeira selecção consistiu na procura de 'palavraschave' (género e sexualidade) em trabalhos disponibilizados em PDF, na pesquisa de títulos e temas, em leituras 'na diagonal', entre outras estratégias.

5 Além dos critérios referidos, foram evitados, à partida, a análise da maioria dos trabalhos que se inserem na área da Demografia/ Geografia da População, isto pela recorrência ao uso de variáveis/categorias como 'sexo/homem/mulher' de forma apriorística, e sem que a problematização de relações de género e/ou sexualidade tendam a ocupar centralidade nos respectivos trabalhos, ocorrendo, muitas vezes, situações de 'invisibilidade'. Além disso, alguns dos trabalhos analisados não foram selecionados, mesmo podendo existir uma referência às questões de género e sexualidade, devido ao facto de tais questões tenderem a ser 'arrumadas' numa breve linha, geralmente na introdução, como dimensões que os autores(as) consideram relevantes, mas que 
raramente acabam por ser aprofundadas posteriormente.

6 Por exemplo, a não inclusão dos trabalhos de Isabel Pato e Silva (SILVA e CROZAT, 2007; SILVA, 2010), os quais, em alguns pontos, poderá ser considerado como um projecto de 'queerização' do conhecimento geográfico, incorporando críticas da teoria queer e outras discussões com proximidades a esta, mas que não se esgotam na teoria queer, como sejam a actor-network theory, a performatividade e a teoria não-representacional.

7 “ $(\ldots)$ heteronormativity is a term that captures the imposition of certain beliefs about sexuality through social institutions and social policies. These ideas concern a "normative heterosexuality" in which it is assume individuals' sexual identities conform to a social norm of heterosexual love, sex and reproduction." (HUBBARD, 2008, p 646).

8 "Num exercício de síntese, pode dizer-se que a teoria queer parte de cinco ideias centrais. Em primeiro lugar, as identidades são sempre múltiplas, compostas por um número infinito de "componentes de identidade" (...) que podem articular-se de inúmeras formas. Em segundo lugar, qualquer identidade construída - como, de resto, todas são - é arbitrária, instável e excludente, uma vez que implica o silenciamento de outras experiências de vida. (...) Em terceiro lugar, ao invés de defender o abandono total da identidade enquanto categoria política, a teoria queer propõe que reconheçamos o seu significado permanentemente aberto, fluído e passível de contestação, abordagem que visa encorajar o surgimento de diferenças e a construção de uma cultura onde a diversidade é acolhida. (...) Em quarto lugar, a teoria queer postula que a teoria ou política de homossexualidade centrada no 'homossexual' reforça a dicotomia hetero/homo, fortalecendo o actual regime sexual que estrutura e condiciona as relações sociais ocidentais. (...) Por fim, a teoria queer apresenta-se enquanto proposta de teorização geral sobre a "sexualização de corpos, desejos, acções, identidades, relações sociais, conhecimentos, cultura e instituições sociais" (SEIDMAN, 1996, p. 3), cruzando muitos campos de saber." (SANTOS, 2006, p. 7 - 8).

9 "Ora, fala-se, em primeiro lugar da representação como 'verdade parcial' porque, sendo produzida necessariamente por um autor, se encontra sempre afectada pelas prioridades que definem o seu ponto de vista e pelo quadro contextual em que esse mesmo autor está inserido. Fala-se ainda de uma verdade parcial porque todas as representações partem não só de um 'campo de referência extratextual', ou seja, dos dados do mundo real, mas também de um 'campo de referência intertextual', que, no fundo, diz respeito ao contexto produzido por outros textos." (HENRIQUES, 1996, p. 51). Sendo que, como salienta o autor, partindo das posições que na geografia introduzem a hermenêutica, “(...) qualquer forma de representação, não podendo ser confundida com a realidade, nem por isso deixa ser, em parte, emanação dessa mesma realidade." (HENRIQUES, 1996, p. 51). Esta questão leva à necessidade da Geografia reconhecer “(...) de que se trata apenas de uma entre as diversas visões possíveis do mundo, sem superioridade inata, inerente, absoluta, ou indiscutível face a outras formas de representação, pensadas e exprimidas noutros registos: uma visão cuja originalidade resulta de se encontrar sujeita às regras e às lógicas da ciência e que só nessa linguagem específica, nesse modo de raciocínio, tem validade e pode ser legitimada." (HENRIQUES, 1996, p. 52).

10 Cujas principais questões aparecem apresentadas de forma 'sintética' na seguinte problematização de Joseli Silva: "As ausências da produção do saber e do poder tornaram-se focos de interesse e concebidas como contraditórias e complementares às presenças e expressões geográficas. A percepção da falta de grupos sociais ou temas que estão fora do discurso hegemônico da Geografia, não mais se justificava por sua aespacialidade ou sua inadequação como objetos deste campo científico, mas pela hegemonia de determinada forma de conceber a produção do espaço, pretensamente universal e neutra, que abafava a voz dos grupos não-hegemônicos." (SILVA, 2010, p. 42). Sendo que 'epistemologia masculina' estabeleceu-se “(...) relegando, segundo a geógrafa Linda McDowel (1999) a visão feminina para um segundo plano, gerando-se uma forte invisibilidade do seu trabalho e da sua maneira de pensar no processo de produção de espaço por meio de alguns fatores fundamentais tais como o facto da ciência geográfica privilegiar paisagens e tendências hegemónicas, assim como a tradição na abordagem de aspetos físicos e visíveis no espaço, o apego a dados quantitativos, a busca da neutralidade científica e a abordagem economicista da perspetiva marxista." (ALVES, 2013, p. 16).

11 "Knowledge is produced in specific contexts or circumstances and the acknowledgment of the situatedness of knowledge leads to the recognition of 
the importance of the 'position' or 'positionality' of the researcher, of her/his specific embodied locations (ROSE, 1993; VALENTINE, 2002). In this perspective it is important that researchers are self-reflexive assuming explicit positions in order to overcome false notions of neutrality." (FERREIRA, 2010, p. 39).

12 "Queer methodologies deconstruct truth claims, question dualistic ontology and queer straight lines." (MANNING, 2009, p. 1).

13 Nós consideramos o conceito de 'interseccionalidade' como significando o complexo, irredutível, conjunto de efeitos variados, e variáveis que surgem quando eixos múltiplos de diferenciação económico, político, cultural, psíquico, subjetivo e experienciais - se intersectam em contextos históricos específicos. O conceito enfatiza que diferentes dimensões de vida social não podem ser separadas em discreto e puras vertentes. - Avtar Brah" (VIEIRA, 2010e, p. 22)

14 In particular, there has in human geography been a shift towards what Sayer and Morgan have termed intensive methods (see also ALLEN and MCDOWELL, 1989) involving detailed, often casestudy based methods to uncover the social processes and relations of power that lie beneath geographical patterns." (MCDOWELL, 1992, p. 400).

15 É de referir, não como exemplo mais paradigmático de uma 'análise dicotómica', mas sim como exemplo das dificuldades que tal posição implica ao nível da sua implementação, os trabalhos de Jorge Malheiros (MALHEIROS et al, 2010; 2011). Nestes, a discussão desenvolvida pelos autores, é apresentada como partindo de uma análise relacional entre os dois 'sexos', defendendo estes que se trata de um estudo de género para o qual é referida a necessidade de ser feita uma comparação entre mulheres e homens e não focando-sese focando unicamente num dos géneros, considerado os autores que as análises que se focam num dos géneros tendem a correr o risco do essencialismo devido ao facto de tender a revelar uma perspectiva dicotómica entre 'homem' e 'mulher'. Ora, esta visão, apesar de se apresentar como não dicotómica, traz, contudo, algumas questões, em particular pelo facto de, apesar da visão relacional entre os dois géneros que diz privilegiar, estudando "(...) um em função do outro (...)" (MALHEIROS et al, 2010, p. 39), e da referência ao perigo do essencialismo, é de questionar a consideração feita relativamente à fluidez existente entre 'homem' e 'mulher', sendo que foram mantidas estas duas categorias de forma apriorística, o que tende a essencializar tais conceitos. Ou seja, e como refere Joseli Silva, importa considerar que: "[u]tilizar o conceito de gênero, que implica uma postura relacional dos universos femininos e masculinos, não leva à necessidade de análises comparativas envolvendo homens e mulheres, embora haja tradição deste perfil de produção científica. A dimensão relacional que a ideia de gênero concebe é a compreensão de que os seres não estão isolados e estáticos e os recortes sociais estabelecidos no processo de pesquisa devem ser considerados de forma relacional e processual na estrutura socioespacial a que pertencem." (SILVA, 2010, p. 40).

16 Relativamente a este ponto, importa problematizar a análise feita por Paulo Nossa (2001), recuperada em Claudete Moreira (2003). Paulo Nossa, no referido texto, começa por fazer uma problematização sobre a validade da abordagem da dimensão de género na geografia, em particular, tendo em consideração a sua “(...) materialização espacial, sob pena de resvalarmos para uma análise tendencialmente mais sociológica do que geográfica, pese o facto de a geografia ser considerada uma ciência social, cujo objecto formal é o espaço geográfico" (NOSSA, 2001, p. 295)". Tratando-se de uma afirmação que apresenta a sua validade, em particular se tivermos em conta a necessidade de que tais geografias estejam atentas a abordagens que possam ser vistas como a-espaciais, contudo, tal observação não nos deverá fazer cair no erro de desconsiderar os aspectos tidos como mais 'imateriais', isto pela 'falsa' oposição entre material-imaterial, tal como salientado por Larry Knopp.

17 Neste caso, fazendo uso de conceitos que, apesar de igualmente se enquadrarem numa bibliografia crítica - Baudrillard em particular -, não é a bibliografia que geralmente aquela tende a ser referenciada na área das geografias de género e sexualidade.

18 "O território, como ponto de partida para o estudo dos fenómenos sociais, poder ser, em muitas situações, a melhor via para um conhecimento descompartimentado. Condições de várias ordens, cujo estudo compete a diversos domínios científicos, conjugam-se de múltiplas formas na definição das manifestações sociais e essa articulação concretiza-se no território.” (ANDRÉ, 1990, p. 335).

19 A forma de analisar as relações entre sociedade e território é influenciada por Edward Soja, focando-se nos territórios "marginalizados por 
discriminações", sendo que estes territórios, "na margem", poderão ter o potencial de construção de identidades flexíveis/híbridas e já não vistas de forma dicotómica/binária, influenciado um outro território, um "terceiro espaço", no qual é "(...) construindo novas formas de identificação e de relacionamento onde emergem identidades híbridas (BHABHA, 1994), cujos processos estão na origem de algo diferente, novo, uma nova área de negociação e de sentido ou de representação.” (QUEIRÓS, 2010a, p. 3).

20 Em Azevedo et al (2009), os autores referem como houve a tendência para uma descorporização do conhecimento, a "subtracção da experiência sensorial" em benefício de uma "experiência ocularcêntrica" com o objectivo de legitimação "científica" da disciplina, experiência ocularcêntrica esta que parte da "(...) mente como palco de representações e o olho, e respectivos aparatos e próteses de visualização, como aparelho que devolve à mente uma visão objectiva dos fenómenos, legitima um sem-número de textos e discursos que partem de um quadro relacional assente sobre a fractura entre sujeito e objecto de conhecimento." (AZEVEDO et al, 2009, p. 11).

21 Por exemplo, uma possível visão crítica chamaria a atenção ao enfoque dado por Fernanda Cravidão (CRAVIDÃO e SANTOS, 2010a, 2010b) apenas nos processos de matrimónio, privilegiando, dessa forma, a análise dos comportamentos heterossexuais (o casamento civil entre pessoas do mesmo sexo foi aprovado em 2010, numa altura posterior ao trabalho empírico realizado).

22 Algo que poderá ser apontado, em parte, a um trabalho de Luís Mendes, no qual o autor salienta que os processos de gentrificação protagonizados por mulheres poderão ter um potencial emancipatório ao nível da quebra da dicotomia homem/mulher, mesmo que referindo que tal é conseguido através da reivindicação do espaço económico e urbano anteriormente exclusivo do 'homem' a partir da reivindicação, por parte das mulheres, relativamente à actividades/funções que poderão ser tradicionalmente associadas a um papel de desigualdade de género, como é observado na referência à luta por "centros de apoio a crianças (...), melhor cuidado comunitário para idosos e deficiente, de modo que elas possam temporariamente libertar-se do papel de auxiliares e reivindicarem um lugar de direito na força de trabalho capitalista paga” (MENDES, 2010, p. 93).

23 Sendo de salientar, novamente, os trabalhos de Isabel Pato e Silva (SILVA e CROZAT, 2007;
SILVA, 2010).

\section{Referências}

ALVES, Ana. Moda, Cultura e Corporeidades. GeoPlanUM, II Edição, p. 11 $-19,2013$.

ANDRÉ, Isabel. O Género em Geografia Introdução de um novo tema. Finisterra, v. 50, p. $331-348,1990$.

ANDRÉ, Isabel. O Falso Neutro em Geografia Humana - Género e relação patriarcal no emprego e no trabalho doméstico. 1993. Dissertação (Mestrado em Geografia Humana) - Universidade de Lisboa, Lisboa.

ANDRÉ, Isabel; FONSECA, Maria Lucinda. Casamento e mobilidade. V Coloquio Ibérico de Geografia, 1989.

ANDRÉ, Isabel; HENRIQUES, Eduardo Brito. Práticas de lazer, território e género. VI Colóquio Ibérico de Geografia, Porto, 1992.

AZEVEDO, Ana; PIMENTA, José; SARMENTO, João (Orgs.). Geografias do Corpo. Ensaios de Geografia Cultural. Porto: Livraria Figueirinhas, 2009.

CRAVIDÃO, Fernanda Delgado; SANTOS, Maria. Convivências e casamentos no processo migratório. Trabalhadores Brasileiros na Região Centro de Portugal. 2010a. Fonte: $<$ http://www.abep.nepo.unicamp.br/encontro2 010/docs_pdf/tema_6/abep2010_2120.pdf $>$. Acesso: 17/02/2014.

CRAVIDÃO, Fernanda Delgado; SANTOS, Maria. Matrimônios e Convivências. Trabalhadores brasileiros na Região Centro de Portugal. 2010b. Fonte: $<$ http://www.fazendogenero.ufsc.br/9/resourc es/anais/1278278787_ARQUIVO_Matrimoni 
oeconvivencias. TrabalhadoresbrasileirosnaRe giaoCentrodePortugal.pdf $>$.

Acesso:

17/02/2014.

FERREIRA, Eduarda. Geographies of (in)equalities: space and sexual identities. 2010.

Fonte:

$<$ https://sites.google.com/site/geographiesofin clusion/Geographiesofinequalities.pdf?attredi rects $=0>$. Acesso: 17/02/2014.

FERREIRA, Eduarda. Identidades sexuais e ciberespaço: Visibilidade LGBT no ciberespaço português. 2011a. Fonte: $<$ http://www.academia.edu/1529496/Sexual_i dentities_and_cyberspace_LGBT_visibitiy_in the Portuguese_cyberspace $>$. Acesso: $17 / 02 / 2014$.

FERREIRA, Eduarda. Questões de género e orientação sexual em espaço escolar. 2011b. Fonte:

$<$ http://www.academia.edu/1529514/Gender sexual orientation_and_school $>$. Acesso: $17 / 02 / 2014$.

FERREIRA, Eduarda. Collaborative Webmapping: Creating Layers of Lesbian Visibility. $2012 . \quad$ Fonte: $<$ http://www.academia.edu/2075753/Collabor ative_Webmapping_Creating_Layers_of_Les bian_Visibility>. Acesso: 17/02/2014.

FERREIRA, Eduarda; SALVADOR, Regina. Representações de Espaços Públicos de (Des)Igualdade: Entre o Físico e o Virtual. 2010. Fonte: $<$ http://web.letras.up.pt/xiicig/resumos/201.pd f>. Acesso: 17/02/2014.

FERREIRA, Eduarda; SALVADOR, Regina. Sensing the Landscape: Collaborative Emotion Mapping in Urban Spaces. 2012. Fonte:

$<$ http://www.academia.edu/2075754/Sensing the_Landscape_Collaborative_Emotion_Map
ping_in_Urban_Spaces>.

Acesso:

17/02/2014.

GREGORY, Derek; JOHNSTON, Ron; PRATT, Geraldine; WATTS, Michael; WHATMORE, Sarah. The dictionary of human geography. 5th edition. Singapure: Wiley-Blackwell, 2009.

HENRIQUES, Eduardo Brito. A problemática da representação no pensamento geográfico contemporâneo. Inforgeo, v. 11, p. $43-53,1996$.

HENRIQUES, Eduardo Brito. Corpo, pessoa e espaço geográfico: repensar o humano na Geografia Humana. Geophilia - O Sentir e os Sentidos da Geografia. Homenagem a Jorge Gaspar, CEG: Lisboa, 2007.

HOFF, Benedict. Uma experiência com a linguagem do cinema: objectivos, efeitos e consequências. In: AZEVEDO, Ana; PIMENTA, José; SARMENTO, João (Orgs.) Geografias do Corpo. Ensaios de Geografia Cultural. Porto: Livraria Figueirinhas, 2009, p. $123-144$.

HOTTOLA, Petri. Gender and the body in tourism Geography. Série Investigação 2004/1, Geo-Working Papers, Universidade do Minho, $2004 . \quad$ Fonte: $<\mathrm{http}$ ://repositorium.sdum.uminho.pt/handle/ 1822/4645>. Acesso: 17/02/2014.

HUBBARD, Phill. Here, there, everywhere: the ubiquitous geographies of heteronormativity. Geography Compass, v. 2, n. 3, p. $640-658,2008$.

KNOPP, Larry. From Lesbian and Gay to Queer Geographies: Pasts, Prospects and Possibilities. In: BROWNE, Kath; LIM, Jason; BROWN, Gavin (Coord.). Geographies of sexualities: theory, practices and politics. Hampshire: Ashgate, 
2007, p. $21-28$.

LOPES, Ermelinda. Mulheres e Ambiente: A problemática da apanha de inertes na Ilha de Santiago (Cabo Verde). 2010. Dissertação (Mestrado em Geografia) Universidade de Coimbra, Coimbra.

LOPES, Ermelinda; CUNHA, Lúcio. A mulher e a extração clandestina de inertes em Cabo Verde. Mercator, v. 11, n. 25, p. 71 86, 2012.

MALHEIROS, Jorge; RODRIGUES, Frederica; PADILLA, Beatriz. A dimensão psico-social do empreendedorismo imigrante feminino. Revista Migrações, v. 8, p. 93 122, 2011.

MALHEIROS, Jorge; RODRIGUES, Frederica; PADILLA, Beatriz. Mulheres imigrantes empreendedoras. CIG. 2010. Fonte:

$<$ http://www.igualdade.gov.pt/IMAGES/STO RIES/DOCUMENTOS/DOCUMENTACAO/ PUBLICACOES/MULHERES_EMIGRANT ES_EMPREENDEDO.PDF $>$. Acesso: $17 / 02 / 2014$.

Manning, Elizabeth. Queerly Disrupting Methodology. 2009. Fonte: $<$ http://www.kvinfo.su.se/femmet09/papers/p df/Manning.pdf $>$. Acesso: 17/02/2014.

MCDOWELL, Linda. Doing Gender: Feminism, Feminists and Research Methods in Human Geography. Transactions of the Institute of British Geographers, v. 17, n. 4, p. $399-416,1992$.

MEDEIROS, Isabel. Serão explicáveis os conflitos violentos em África? - Notas de Leitura. Finisterra, v. 89, p. 181 - 204, 2010.

MENDES, Luís. O Lugar do Género na Produção de Gentrificação e de Novas Procuras Residenciais no Centro Histórico de
Lisboa. Revista Latino-americana de Geografia e Gênero, v. 1, n. 1, p. 89 - 105, 2010.

MOREIRA, Claudete. Espaço(s) e Ambiente(s) - trajectórias femininas na Região Centro. In: CAETANO, Lucília (Org.) Território, Ambiente e Trajetórias de Desenvolvimento. Coimbra: Centro de Estudos Geográficos, 2003, p. 259 - 284.

MOREIRA, Claudete. Tempo livre, lazer e consumo na sociedade urbana contemporânea, segundo os géneros. In: SANTOS, Norberto; GAMA, António (Coords.). Lazer: da libertação do tempo à conquista das práticas. Coimbra: Imprensa da Universidade de Coimbra, 2008, p. 179 207.

MOREIRA, Claudete. A Geografia e o Género: Um encontro urbano Os tempos e os espaços nos territórios de Coimbra. Coimbra: Fundação Eng. ${ }^{\circ}$ António de Almeida, 2010.

MOREIRA, Claudete; SANTOS, Norberto. O lazer e a noite - imagens de uma cidade universitária: Coimbra. In: SANTOS, Norberto; GAMA, António (Coords.). Lazer: da libertação do tempo à conquista das práticas. Coimbra: Imprensa da Universidade de Coimbra, 2008, p. 247 - 271.

NADAIS, Catarina; SANTOS, Norberto. O lazer, o erotismo e a sociedade contemporânea. Revista de Geografia e Ordenamento do Território, v. 1, p. 143 163, 2012.

NOSSA, Paulo. Abordagem Geográfica da Relação Saúde/Doença - o caso da SIDA. 1995. Dissertação (Mestrado em Geografia Humana) - Faculdade de Letras da Universidade de Coimbra, Coimbra. 
NOSSA, Paulo. Desenvolvimento e feminização: alibis e igualdades. In: CAETANO, Lucílica (Coord.). Território, Inovação e Trajectórias de Desenvolvimento. Coimbra: Centro de Estudos Geográficos, 2001.

OLIVEIRA, João Manuel; PINTO, Pedro; PENA, Cristiana; COSTA, Carlos Gonçalves. Feminismos Queer: Disjunções, Articulações e ressignificações. ex æquo, v. 20, p. 13 - 27, 2009.

PEIXOTO, João; SOARES, António Goucha; COSTA, Paulo Manuel; MURTEIRA, Susana; PEREIRA, Sónia; SABINO, Catarina. O Tráfico de Migrantes em Portugal: Perspectivas Sociológicas, Jurídicas e Políticas. Lisboa: ACIME, 2005.

PEREIRA, Sónia. Trabalhadores imigrantes de origem africana: precariedade laboral e estratégias de mobilidade geográfica. Revista Migrações, v. 2, p. $47-71,2008$.

PEREIRA, Sónia. Imigrantes e Precariedade Laboral: O caso dos trabalhadores de origem africana. Precários em Portugal: entre a fábrica e o call center. In: MATOS, José Nuno; DOMINGOS, Nuno; KUMAR, Rahul (orgs). Le Monde Diplomatique e Edições 70: Lisboa, 2011.

PEREIRA, Sónia. Replacement Migration and Changing Preferences: The Case Of Immigrant Workers In Cleaning and Domestic Service In Portugal. Journal of Ethnic and Migration Studies, v. 39, n. 7, p. 1141 1158, 2013.

PEREIRA, Sónia; VASCONCELOS, João. Human Trafficking And Forced Labour Case studies and responses from Portugal. ILO: Geneva, 2008.

PHILLIPS, Richard. Literaturas de viagem e cartografias da sexualidade. A 'Sotadic Zone' de Richard Burton. In: AZEVEDO, Ana; PIMENTA, José; SARMENTO, João. Geografias, Pós-Coloniais. Porto: Figueirinhas, 2007, p. $71-110$.

PINK, Bradley. Que(e)rying Cape Town: Touring Africa's 'Gay Capital' eith the Pink Mapa. In: SARMENTO, João; HENRIQUES, Eduardo Brito. Tourism in the Global South. Lisboa: Centro de Estudos Geográficos, 2009, p. 65 - 90.

QUEIRÓS, Margarida. Rumo à Construção de uma Agenda de Investigação 'Género e Ambiente' em Portugal. Revista Latinoamericana de Geografia e Gênero, v. 1, n. 1, p. : 106 - 115, 2010 b.

QUEIRÓS, Margarida. Políticas Públicas para a Igualdade. Uma Reflexão a Partir do Guia para o Combate à Discriminação nos Municípios. ex aequo, v. 25, p. 137 - 148, 2012.

QUEIRÓS, Margarida (Coord.). Guia para o combate à discriminação nos Municípios. Planear para todos e todas, planear a diversidade. IGOT-UL e CIG: Lisboa. (2010a). Fonte: $<$ http://195.23.38.178/cig/portalcig/bo/docum entos/GuiaCombate\%20Discrimina_ISBN_C IG.PDF>. Acesso: 17/02/2014.

QUEIRÓS, Margarida (coord.). Políticas de Igualdade nas Autarquias Locais. IGOTUL/CEG-UL e CIG: Lisboa. 2011. Fonte: $<$ http://www.mopt.org.pt/uploads/1/8/5/5/185 5409/polticas_de_igualdade_nas_autarquias_1 ocais.pdf $>$. Acesso: 17/02/2014.

QUEIRÓS, Margarida; COSTA, Nuno. Knowledge on Gender Dimensions of Transportation in Portugal. Dialogue and UniversalismE, v. 3, n. 1, p. $47-69,2012$. 
QUEIRÓS, Margarida; GASPAR, Jorge (Coord.). Género, Território e Ambiente Guia para o Mainstreaming de Género. (2009a). Fonte: $<$ http://www.igualdade.gov.pt/IMAGES/STO RIES/DOCUMENTOS/DOCUMENTACAO/ OUTROSDOCUMENTOS/GUIA MAINST REAMING_GENERO.PDF>. Acesso: $17 / 02 / 2014$.

QUEIRÓS, Margarida; GASPAR, Jorge (Coord.). Género, Território e Ambiente Estudo de diagnóstico e criação de indicadores de género na área do ambiente e território. (2009b). Fonte: $<$ http://www.igualdade.gov.pt/IMAGES/STO RIES/DOCUMENTOS/DOCUMENTACAO/ RELATORIOS/RELATORIO_GENERO_TE RRITORIO_A_2.PDF $>$. Acesso: 17/02/2014.

ROBERTA, Gilchrist. O corpo dessexuado: a vida interior das mulheres religiosas da Idade Média. In: AZEVEDO, Ana; PIMENTA, José; SARMENTO, Jorão (Coords.). Geografias do Corpo. Ensaios de Geografia Cultural. Porto: Livraria Figueirinhas, 2009, p. $99-122$.

ROCA, Maria de Nazaré; LEITÃO, Nuno. Capital Humano e Desenvolvimento Territorial: Diferenças de Género. In: SANTOS, Norberto; CUNHA, Lúcio (Coords.). Trunfos de uma Geografia Activa - Desenvolvimento Local, Ambiente, Ordenamento e Tecnologia. Coimbra: Imprensa da Universidade de Coimbra, 2011, p. $657-665$.

SANTOS, Ana Cristina. Heteroqueers contra a heteronormatividade: Notas para uma teoria queer inclusiva. Oficina do CES, 239, 2005. Fonte:

$<$ http://www.ces.uc.pt/myces/UserFiles/livros /223_Oficina_do_CES_239_Nov2005.pdf $>$. Acesso: 17/02/2014.
SANTOS, Ana Cristina. Estudos queer: Identidades, contextos e acção colectiva. Revista Crítica de Ciências Sociais,v. 76, p. 3 - 15, 2006.

SARMENTO, João. Searching for Cultural Geography in Portugal. Social and Cultural Geography, v. 9, n. 5, p. 573 - 600, 2008.

SARMENTO, João; ETEMADDAR, Fateme. Nomad Tribal Women and Tourism Development: the Khamseh Tribes, Iran Proceedings of Traditions and Transformations. 2009. Fonte: $<$ https://sites.google.com/site/jsargeo/proceed ings $>$. Acesso: 17/02/2014.

SHARP, Joanne. Feminisms. In: DUNCAN, James; JOHNSON, Nuala; SCHEIN, Richard (Coords.). A Companion to Cultural Geography. Malden: Blackwell Publishing, 2004, p. $66-79$.

SILVA, Isabel Pato. Além-cidade - Jovens, controlo e visibilidade na gestão da pobreza - Os casos da Quinta da Fonte e de Bacalan. 2010. Tese (Doutorado em Geografia Humana) - Universidade de Lisboa, Lisboa.

SILVA, Isabel Pato; CROZAT, Dominique. Apreender a performatividade - Para uma desconstrução do processo de produção discursiva. Cidades- Comunidades e Territórios, v. 14, p. 71 - 86, 2007.

SILVA, Joseli Maria. Geografias feministas, sexualidades e corporalidades: desafios às práticas investigativas da ciência geográfica. Espaço e Cultura, v. 27, p. 39 - 55, 2010.

SILVA, Joseli Maria; VIEIRA, Paulo Jorge. Gênero e Território na Geografia Portuguesa: Entrevista com Margarida Queirós. Revista Latino-americana de Geografia e Gênero, v. 3, n. 1, p. $185-189,2012$. 
VIEIRA, Paulo Jorge. Turismo Gay e Lésbico em Lisboa: entre a oferta e a representação internacional. In: SIMÕES, Jose Manuel; FERREIRA, Carlos Cardoso (Eds.). Turismos de Nicho- Motivações, Produtos, Territórios. Lisboa: Centro de estudos geográficos, 2009, p. $369-385$.

VIEIRA, Paulo Jorge. Aeminiumqueer, a cidade armário - Quotidianos lésbicos e gays em espaço urbano. Revista LatinoAmericana de Geografia e Género, v. 1, n. 1, p. 5 - 13, 2010a.

VIEIRA, Paulo Jorge. Das Espacialidades Queer: notas para alargar o espectro da geografia social. 2010b. Fonte: $<$ http://web.letras.up.pt/xiicig/comunicacoes/ 210.pdf $>$. Acesso: 17/02/2014.

VIEIRA, Paulo Jorge. Mobilidades, Migrações e Orientações Sexuais - percursos em torno das fronteiras reais e imaginárias. ex aequo, v. 24, p. $45-59,2011$ a.

VIEIRA, Paulo Jorge. $\mathbf{O}$ direito à cidade (e ao seu centro) - Debates sobre a utilização do espaço público urbano da cidade de Lisboa pelo movimento LGBT. 2011b. Fonte:

$<$ http://web.letras.up.pt/xiicig/comunicacoes/ 177.pdf $>$. Acesso: 17/02/2014.

VIEIRA, Paulo Jorge. Do 'bairro' e para além do 'bairro' - Heterotopias e Constelações Lésbicas e Gays em Espaço Urbano. (2011c). Fonte: $<$ http://www.fcsh.unl.pt/ egeo/sites/default/fi les/dl/actasgeografiasdeinclusao.pdf $>$.

Acesso: 17/02/2014.

VIEIRA, Paulo Jorge. Heterotopias e Constelações Sexuais - Espacialidades e Quotidianos Lésbicos e Gays em Lisboa. 2011d. Fonte:

$<$ http://www.academia.edu/1702772/HETER
OTOPIAS E CONSTELACOES SEXUAIS ._ESPACIALIDADES_E_QUOTIDIANOS_ LESBICAS_E_GAYS_EM_LISBOA>. Acesso: $17 / \overline{0} 2 / 2014$.

VIEIRA, Paulo Jorge. Espacialidades e Interseccionalidades - Igualdade e Diversidade na Investigação Geográfica. IV Colóquio do Núcleo de Estudos em Espaço e Representações - As múltiplas espacialidades culturais: interfaces regionais, urbanas e rurais, Santa Maria, 2011e.

VIEIRA, Paulo Jorge. Cidades torcidas: uma abordagem conceitual sobre (homo)sexualidades e espaço urbano. XII Simpósio Nacional de Geografia Urbana Ciência e Utopia: por uma Geografia do Possível, 2011f.

Recebido em 15 de dezembro de 2013. Aceito em 10 de fevereiro de 2014. 